\title{
Knowledge and Behaviors of Mothers about Food Safety in Selected Villages at Minia City.
}

\author{
Fatma A. Ali 1, Mona A. Khalifa 2 \& Manar M. Demein 3
}

1. B.Sc. Nursing, Faculty of Nursing, Minia University,

2. Professor of Community medicine, Faculty of Medicine, Minia University,

3. Lecturer of Community Health nursing, Faculty of Nursing, Minia University

\begin{abstract}
Background: Safe food is one of the most important human rights, due to the changes in food production, handling and preparation techniques as well as eating habits, the fact remains that food is the source for microorganisms that can cause illness, and improving the feeding knowledge of households is a way to improve household food security. Aim : The study aimed to assess knowledge and behaviors of mothers about food safety at a Selected Villages in Minia City. Research Design: Descriptive cross-sectional research design. Setting: The study was carried out at Minia villages are (Bani-Ahmed, Maqousa, Sawada and Alborgaya). Sample: A purposive sample of 240 mothers. Tools of Data Collection: Three tools were designed Tool I: "Interviewing structured questionnaire, Tool II: Assessment questionnaire of mothers' knowledge about food safety, it includes two parts: Part (1): "General knowledge about food safety, Part (2): Assessment questionnaire of knowledge about food safety", Tool III "Assessment of behaviors about food safety questionnaire". Results: Current study findings revealed that (50\%) of the studied mothers were illiterate, and $(90 \%)$ are not enrolled in any training, lectures or seminars about food safety $(57.9 \%)$ of them have poor knowledge level and (37.5\%) have satisfactory behavioral level and (55.4\%) reported poor behavior. There was a statistical significant relation between total level of behavior and number of family members ( $p$-value $=0.021$ ). Conclusion: Impairment in the knowledge and behaviors of mothers about food safety. Recommendations: Nurses should emphasis to provide an educational program tailored to each mother in the community about food safety, and healthcare organizations must develop a dedicated funding plan that supports health education about healthy food and food borne illness.
\end{abstract}

Key Words: food safety, food borne illness, food safety Knowledge and behaviors.

\section{Introduction:}

Safe food is one of the most important human rights and in developed society's protection from diseases and improvement of human health is of primary important, and is important for both governments and industries but also for consumers themselves (Zeeshan $\boldsymbol{C}$., 2017). The paragraph not suffient add another paragraph

Food safety include all conditions and measures that are necessary during production, processing, storage, distribution and preparation of food to ensure that is safe and fit for human consumption according to world health organization (Basavanthappa B.T., 2016). The paragraph not suffient add another paragraph

The changes in food production, handling and preparation techniques as well as eating habits, the fact remains that food is the source for microorganisms that can cause illness. The United States Centers for Disease Control and Prevention revealed that the outbreaks of diseases which resulted from consumption of unsafety foods of animal origin had caused approximately 76 million illness, 325,000 hospitalizations and 5000 deaths each year (Gemeda, et al., 2018).

Improving the feeding knowledge of households is a way to improve household food security. On the other hand, at the household level, food security has different components and the amount of food being purchased and consumed is a major element (Mutisya M, et al 2016)

Community health professionals, with their considerable knowledge and unique roles within the local communities they serve, have long been identified as being in an ideal position to be at the forefront of initiatives to tackle healthy lifestyles and inequalities They possess an abundance of knowledge about the health and social needs of their communities and about how those needs can be met. Their everyday experience of home visiting and their long-term knowledge of individuals, families and networks built up over time are valuable resources. As a result, they are well placed to identify community leaders and build alliances with local groups. Community health practitioners also have a role to play in the recruitment and support of lay health workers from the local community who are key players in community health development programs. (Sines, et al., 2013)

\section{Significance of the study}

Good nutrition means maintaining a nutritional states that enables us to grow well and enjoy good health. Traditionally, health care has been concern primarily with healing the sick and helping them to maintain health, but the present days, more emphasis is being given on illness prevention and community health. So a good nutrition is considered as a basic component of health. For which, people should eat hygienic food for maintaining good health (Basavanthappa BT., 2016).

Safe food is one of the most important human rights and in developed society's protection from diseases and improvement of human health is of primary important, and is important for both governments and industries but also for consumers themselves (Zeeshan C., 2017).

Consumers in many societies seemed to be unfamiliar with the ideal refrigeration temperature. Large numbers of consumers did not use a thermometer during food preparation, most consumers lack awareness of the different 
classes of bacteria and especially the pathogenic ones. Food safety has become a major issue of public concern as bacterial outbreaks, and assumed reduced consumer confidence in the healthiness of food products (Zeeshan C., 2017), it is important تكملة

It is important for people to understand how their behavior and activities contribute to the safety of food and how they can decrease the risk of food borne illness. From processes on the farm to practices in the kitchen, human activities play an important role in food safety. (Scallan., et al., 2015)

\section{Aim of the study:-}

Assess knowledge and behaviors of mothers about food safety at a Selected Villages in Minia City.

\section{Research Questions}

1. What are the levels of knowledge and behaviors of mothers regarding food safety?

2. Is there a relationship between levels of knowledge and behaviors of mothers regarding food safety?

3. Is there a relationship between levels of mothers' knowledge and behaviors regarding food safety and their demographic variables?

\section{Subject and methods \\ Research Design}

Descriptive cross-sectional research design was utilized in this study.

\section{Setting: Need more details}

The study was conducted in four villages in Minia City on (2019), Minia city divided into four sectors (North, South, East, and West) then selected one by using a simple random sample from each sector from the total of 42 villages which component of Minia City as a whole, these villages are (Bani-Ahmed, Maqousa, Sawada and Alborgaya).

\section{Sample:}

By using the Epi-info computer software program the required sample size was (240) will be selected randomly as follows: The houses of each village were numbered, and then the first house was randomly chosen, 67 mothers were assessed from Alborgaya village, 57mothers from Maqousa village, 36 mothers from Sawada village, and $\mathbf{8 0}$ mothers from Bani-Ahmed village to cover the total sample size which is $\mathbf{2 4 0}$ mothers. The data collection was continued over four months, starting from August 2019 to December 2019 until the total sample was collected.

\begin{tabular}{|c|c|c|c|c|c|}
\hline villages & $\begin{array}{c}\text { Alborg } \\
\text { aya }\end{array}$ & $\begin{array}{c}\text { Maqou } \\
\text { sa }\end{array}$ & Sawada & $\begin{array}{c}\text { Bani- } \\
\text { Ahmed }\end{array}$ & Total \\
\hline $\begin{array}{c}\text { Total Number of } \\
\text { village's mothers }\end{array}$ & $\mathbf{1 1 2 3 1}$ & $\mathbf{9 6 3 5}$ & $\mathbf{5 8 4 2}$ & $\mathbf{1 3 1 9 2}$ & $\mathbf{3 9 9 0 0}$ \\
\hline Ratio (\%) & $\mathbf{2 8 \%}$ & $\mathbf{2 4 \%}$ & $\mathbf{1 5 \%}$ & $\mathbf{3 3 \%}$ & $\mathbf{1 0 0 \%}$ \\
\hline $\begin{array}{c}\text { Number of the } \\
\text { sample }\end{array}$ & $\mathbf{6 7}$ & $\mathbf{5 7}$ & $\mathbf{3 6}$ & $\mathbf{8 0}$ & $\mathbf{2 4 0}$ \\
\hline
\end{tabular}

Data Collection Tools: Data was collected through three tools: these tools structured and developed by the investigator after a literature review these include:

Tool I: "Interviewing structured questionnaire" developed by the investigator: to assess mothers' sociodemographic characteristics" such as age, social status, educational level, income, employment, number of family members and if the mother was taken any training or lectures about food safety before.

Tool II: Assessment questionnaire of mothers' knowledge about food safety, it includes two parts:

Part (1): "General knowledge about food safety", it developed by the investigator and consists of 23 multiplechoice questions such as, the source of knowledge for the mother regarding food safety, what is the definition of food safety and the used methods to ensure food safety.

Part (2): Assessment questionnaire of knowledge about food safety": adapted from (Kendall, Mitakakis et al., 2004) and modified by the investigator, it consists of 23 multiple-choice questions these questions specifically dealt ?? with respondents' knowledge of personal hygiene, crosscontamination, food-borne diseases, microorganisms, temperature control and hygienic practices.

\section{Scoring system:}

The total score 23 grades, score of one was given for correct answer and score of zero for an incorrect answer or don't know the answer, and categorized as the following:

- Good knowledge: was considered if scoring more or equal than $\geq 75 \%$ of the total score.

- Satisfactory knowledge: was considered if scoring from $50 \%$ to less than $<75 \%$ from total score.

- Poor knowledge: was considered if scoring less than $<50 \%$ of the total score.

Tool III "Assessment questionnaire of mothers' behaviors about food safety": adapted from (Kendall, Mitakakis et al., 2004) and modified by the investigator, it consists of 27 questions.

Scoring system: The total score 27 grades, score of one was given for correct answer and score of zero for an incorrect answer or don't know the answer, and categorized as the following:

- Good knowledge: was considered if scoring more or equal than $\geq 75 \%$ of the total score.

- Satisfactory knowledge: was considered if scoring from $50 \%$ to less than $<75 \%$ of the total score.

- Poor knowledge: was considered if scoring less than $<50 \%$ of the total score.

\section{The Validity of the Tool:}

The study tools were designed after extensive reviewing of literature. The content and validity were done to identify the degree to which the used tools measure what was supposed to be measured. The tools were examined for content coverage, the sequence of items, clarity, relevance, applicability, wording, length, format, and overall appearance. The developed tools were tested by Jury committee consist of five academic experts in field of thesis. They offered a complete assessment of the content and face validity of the instruments.

\section{Reliability of the tool:}

The reliability of the tool was performed to confirm the consistency of the tool. The internal consistency measured to identify the extent to which the items of the tool measured what it was intended to measure. The internal consistency of the tool was assessed with the Cronbach's alpha coefficient.

Cronbach's alpha coefficient of 0.00 indicates no reliability and a coefficient of 1.00 indicates perfect reliability. However, a reliability coefficient of 0.70 is acceptable. 
The internal consistency was assessed and showed a reliability rate by using cronbach's Alpha test.

\section{3- Pilot study:}

The pilot study was conducted before starting actual data collection. It was done on 24 participants $(10 \%)$ of participants who were included in the study after having the ethical approval and permission to access the home visit, to examine the clarity and adequacy of the study tools and estimate the time required for fulfilling it. Depend on the result of the pilot study no modifications or refinements were done, and the participants were included in the actual sample.

\section{Data Collection Procedure:}

- All needed sheets of the tool were printed, and each assessment sheet was coded anonymously.

- Oral permission for voluntary participation was obtained from the participants and the nature and the objectives of the study were explained.

- The investigator met participants in their homes at times that were convenient for them.

- All respondents were interviewed by the investigator to explain nature and purpose of the study and participated voluntarily.

- Data were collected three days per week from (10am to $3 \mathrm{pm}$ ) at homes through about four months from 20 August 2019 to 20 December 2019.

- Face-to-face interviews were conducted using a structured questionnaire to collect information on the knowledge and behaviors of mothers about food safety.

- Data was assured for confidentiality.

- Each participant from the study group was assessed using tool I, II, III in the first interview. Measures were taken to protect the ethical rights of the participants.

- The time spent for each home visit to fill the questionnaire ranged from 30:45 minutes or according to the level of understanding of every participant and the needed explanation.

- After completing, fill out the questionnaire the investigator clarified the correct information about knowledge and behaviors of the participants in case their answers were wrong.

\section{Administrative design:}

- Permission from ethical committee from Minia faculty of nursing to conducted the study.
- Approval from the Mayor of each village were taken.

- Mother's agreement will be a pre request to be included in the study.

- Before carrying out the study the investigator was clarify the aim of the study and it's expected outcomes.

- When it is possible the study participant were provided with feedback about the research outcomes

\section{Ethical Consideration:}

- Authoritative permission to conduct the study was obtained from the research ethics committee of the Faculty of Nursing at Minia University, Dean of nursing faculty and agreement from Egypt academic for research center and technology at Minia University to carry out this study.

- Oral permission was obtained by the investigator from the participants and anonymity and confidentiality were applied by coding all data and protecting the obtained data.

- Participants were acquainted that their data will not be used at any further researches without a second oral consent.

- Each involved participant was acquainted with the objectives, procedure, benefits and nature of the study and that she had the right to withdraw from the study at any time without any rational.

\section{Statistical design:}

The obtained data were summarized, tabulated, and presented using descriptive statistics. Statistical package for the social science (SPSS), version (20) was used for statistical analysis of the data, quantitative data were expressed in the form of mean and standard deviation for measuring dispersion while qualitative data presented as frequency distribution. Chi-square and Fisher exact were used to compare qualitative data and One-way ANOVA tests and independent-sample ttest were used for quantitative data. Correlation between variables was assessed using Pearson correlation coefficients and grade of $r$ was calculated as the following $\mathrm{r}: 0.00-0.24$ no or week correlation, $0.25-0.49$ faire, $0.50-0.74$ moderate and $\geq 0.75$ strong, $P$ value of less than 0.05 considered as cut off for significance, the test of significance $<0.05$ was considered significant is the result $(*),<0.001$ was considered highly significant $(* *)$ and coefficient was done by using person correlation test. Fisher's Exact Test is a way to test the association between two categorical variables. When in case of small cell sizes (expected values less than5).

Results:-

Table (1): Percentage and Distribution of demographic data of the studied mothers $(\mathrm{N}=240)$.

\begin{tabular}{|c|c|c|}
\hline \multirow[t]{2}{*}{ Socio-demographic data } & \multicolumn{2}{|c|}{ Study sample $N=\mathbf{2 4 0}$} \\
\hline & No & $\%$ \\
\hline \multicolumn{3}{|l|}{ Mother age / years } \\
\hline $18-29$ & 87 & 36.3 \\
\hline $30-39$ & 88 & 36.7 \\
\hline $40-49$ & 40 & 16.7 \\
\hline $50-59$ & 23 & 9.6 \\
\hline 60 and more & 2 & .8 \\
\hline \multicolumn{3}{|c|}{$\begin{array}{ll}\text { Mean } \pm \text { SD } & 35.05 \pm 9.90 \\
\end{array}$} \\
\hline \multicolumn{3}{|l|}{ Marital status } \\
\hline Married & 217 & 90.4 \\
\hline Widow & 9 & 3.8 \\
\hline Divorced & 14 & 5.8 \\
\hline \multirow{2}{*}{\multicolumn{3}{|c|}{$\frac{\text { Education Level }}{\text { Illiterate }}$}} \\
\hline & 120 & $50 \%$ \\
\hline
\end{tabular}


Minia Scientific Nursing Journal (Print - ISSN 2537-012X) (Online - ISSN 2785-9797) Vol. (10) No. (1) December 2021

\begin{tabular}{|c|c|c|}
\hline \multirow[t]{2}{*}{ Socio-demographic data } & \multicolumn{2}{|c|}{ Study sample $N=\mathbf{2 4 0}$} \\
\hline & No & $\%$ \\
\hline Read and write & 86 & 35.8 \\
\hline secondary education & 18 & 7.5 \\
\hline University education & 16 & 6.7 \\
\hline \multicolumn{3}{|l|}{ Working state } \\
\hline Employee & 40 & 7 \\
\hline House wife & 200 & 83 \\
\hline \multicolumn{3}{|l|}{ Income } \\
\hline $1000-2000 \mathrm{LE}$ & 141 & 58.8 \\
\hline More than $2000-3000 \mathrm{LE}$ & 86 & 35.8 \\
\hline More than $3000 \mathrm{LE}$ & 13 & 5.4 \\
\hline \multicolumn{3}{|l|}{ Number of family members } \\
\hline 2 & 33 & 13.8 \\
\hline $3-4$ & 107 & 44.6 \\
\hline $5-6$ & 88 & 36.7 \\
\hline more than 6 & 12 & 5.0 \\
\hline
\end{tabular}

Table (1): This table show that more than two third of the studied mothers (73\%) with age ranged from 18:39 with mean age (Mean \pm SD $35.05 \pm 9.900)$. Most of the studied participant were married $(90.4 \%$ )and about half of them ( $50 \%$ ) were illiterate, and about $(7 \%)$ of them were university education, more than half of the studied women $(83 \%)$ were house wives, and more than half with income more than 1000:2000 L.E ( 58.8\%) and about one third of them (35.8\%) with income from 2000:3000 L.E, and nearly to half $(44.6 \%)$ with family members ranged from $3: 4$ members.

Table (2): Percentage Distribution of the studied mothers as regards to exposure to knowledge sources or events related to food safety $(\mathbf{N}=\mathbf{2 4 0})$.

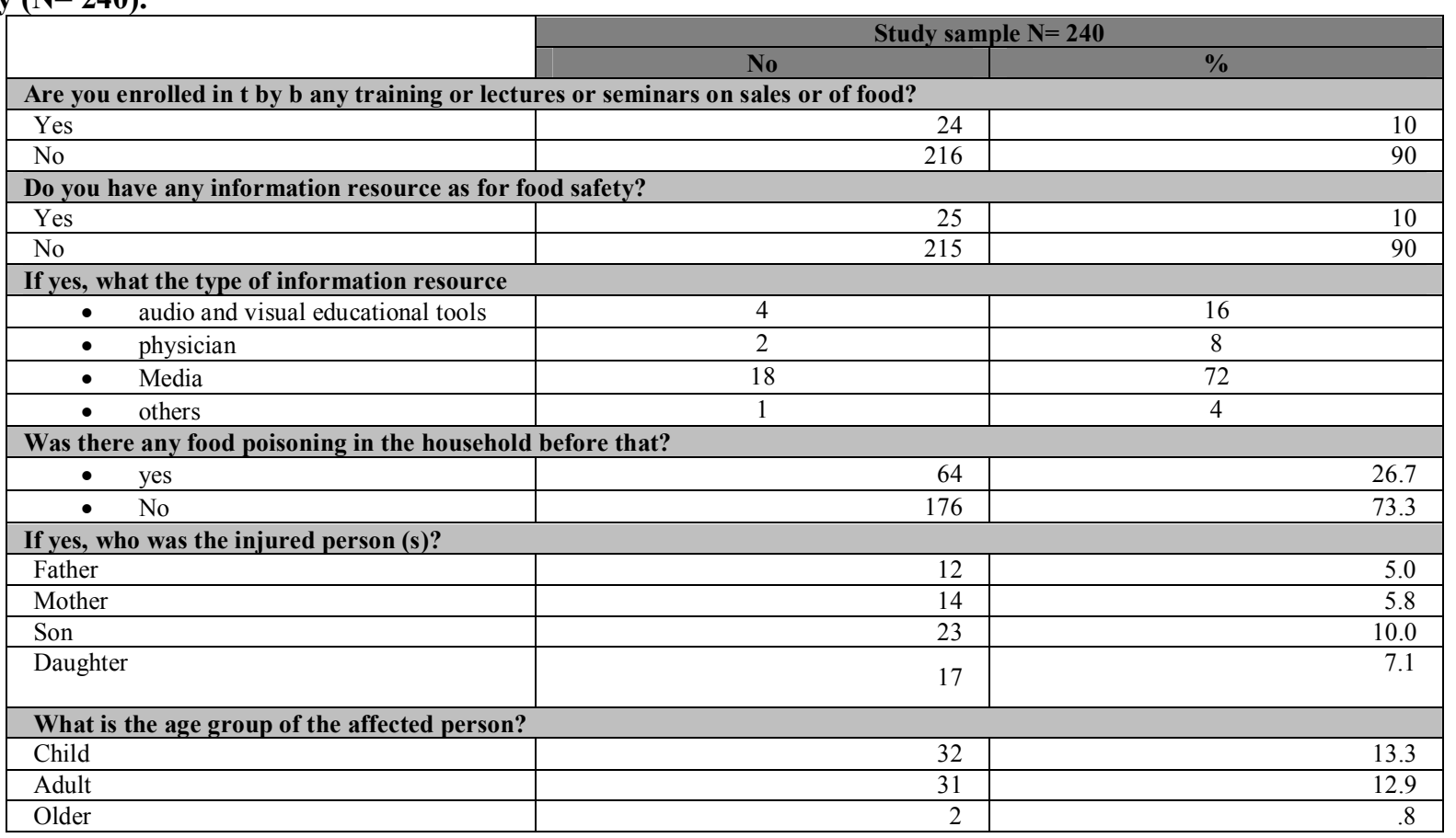

Table (2) This table show that the majority of sample of the studied mothers $\mathbf{( 9 0 \% )}$ are not enrolled in any training, lectures or seminars about food safety, and $\mathbf{( 9 0 \% )}$ of them have not any information resources as for food safety, and (72\%) of mothers that have information resources come from the media, and the majority of the studied mothers $\mathbf{( 7 3 . 3 \% )}$ have no any food poisoning cases in the households.

Table (3): Mean score of knowledge for studied mothers regarding food safety $(\mathrm{N}=\mathbf{2 4 0})$ :

\begin{tabular}{|l|l|l|}
\hline & Max. Score & Mean \pm SD \\
\hline General Knowledge about food safety and food poisoning & 7 & $3.05 \pm 3.57$ \\
\hline Knowledge about hygiene during food preparation & 7 & $4.33 \pm 5.34$ \\
\hline Knowledge about food preservation & 7 & $4.25 \pm 2.06$ \\
\hline Knowledge about cooking food & 5 & 4.7 \\
\hline Knowledge about food separation & 5 & $0-7$ \\
\hline Total score of knowledge & 31 & $4.81 \pm 2.01$ \\
\hline
\end{tabular}

- Max. score = Number of items in each category.

Table (3): This table mentioned that knowledge about hygiene during food separation represented the highest knowledge for studied mothers regarding food safety with mean age 4.81 \pm 2.01 and knowledge about food poisoning represented the lowest knowledge for studied mothers regarding food safety with ( Mean \pm SD 3.05 \pm 3.57 ). 
Minia Scientific Nursing Journal (Print - ISSN 2537-012X) (Online - ISSN 2785-9797) Vol. (10) No. (1) December 2021

Table (4): Mean score of behavior of studied mothers regarding food safety $(\mathrm{N}=240)$ :

\begin{tabular}{|l|c|c|}
\hline & Max. Score & Mean \pm SD \\
\hline Behavior during hygiene during food preparation & 32 & $8.78 \pm 2.81$ \\
\hline Behavior during cooking food & 16 & $30.54 \pm 2.11$ \\
\hline Behavior during food preservation & 40 & $18-32$ \\
\hline Behavior during food separation & 24 & $18.60 \pm 3.22$ \\
\hline Total score of Behavior & 112 & $21.85 \pm 2.14$ \\
\hline
\end{tabular}

- $\quad$ Max. score $=$ Number of items in each category $\times$ number of maximum response

Table (4): This table mentioned that hygiene behavior during food preservation represented the highest behavior of studied mothers regarding food safety with Mean \pm SD 18.60 \pm 3.22 and behavior during cooking food represented the lowest behavior of studied mothers regarding food safety with Mean \pm SD 30.54 \pm 2.11

Table (5): Percentage and distribution of the studied mothers regarding the total level of knowledge and behavior in food safety $(\mathbf{N}=\mathbf{2 4 0})$ :

\begin{tabular}{|c|c|c|c|c|c|c|}
\hline & \multicolumn{2}{|c|}{ Good } & \multicolumn{2}{|c|}{ Satisfactory } & \multicolumn{2}{|c|}{ Poor } \\
\hline & No. & $\%$ & No. & $\%$ & No. & $\%$ \\
\hline Mothers' knowledge level & 11 & 4.6 & 90 & 37.5 & 139 & 57.9 \\
\hline Mean\% $\%$ SD & \multicolumn{6}{|c|}{$66.23 \pm 15.94$} \\
\hline Mothers' behavioral level & 4 & 1.6 & 103 & 42.9 & 133 & 55.4 \\
\hline Mean $\% \pm$ SD & \multicolumn{6}{|c|}{$74.44 \pm 12.70$} \\
\hline
\end{tabular}

Table (5): show that more than half of the studied mothers have poor knowledge level $(57.90 \%)$.with (Mean\% \pm SD66.23 $\pm \mathbf{1 5 . 9 4})$. More than half of the studied mothers (55.4\%) have poor behavioral level with (Mean $\% \pm$ SD 74.44 $\pm \mathbf{1 2 . 7 0 )}$.

Table (6): Relationship between some socio demographic characteristics of the studied mothers and their total level of knowledge regarding food safety $(\mathrm{N}=\mathbf{2 4 0})$

\begin{tabular}{|c|c|c|c|c|c|}
\hline \multirow[t]{2}{*}{ Socio-demographic data } & \multirow[t]{2}{*}{$\mathbf{N}$} & \multicolumn{3}{|c|}{ Total level of knowledge } & \multirow[t]{2}{*}{$P$-value } \\
\hline & & Good $(n=109)$ & satisfactory $(n=120)$ & Poor $(n=11)$ & \\
\hline \multicolumn{5}{|l|}{ Mother age / years } & \multirow[t]{6}{*}{0.517} \\
\hline $18-29$ & 87 & 34 & 50 & 3 & \\
\hline $30-39$ & 88 & 33 & 52 & 3 & \\
\hline $40-49$ & 40 & 15 & 23 & 2 & \\
\hline $50-59$ & 23 & 8 & 13 & 2 & \\
\hline 60 and more & 2 & 0 & 1 & 1 & \\
\hline \multicolumn{5}{|l|}{ Marital status } & \multirow[t]{4}{*}{$0.013 *$} \\
\hline Married & 217 & 87 & 122 & 8 & \\
\hline Widow & 9 & 0 & 8 & 1 & \\
\hline divorced & 14 & 3 & 9 & 2 & \\
\hline \multicolumn{5}{|l|}{ Education Level } & \multirow[t]{5}{*}{$0.012 *$} \\
\hline illiterate & 16 & 7 & 7 & 2 & \\
\hline Read and write & 23 & 12 & 9 & 2 & \\
\hline secondary education & 115 & 67 & 46 & 2 & \\
\hline University education & 86 & 56 & 25 & 5 & \\
\hline \multicolumn{5}{|l|}{ Working state } & \multirow[t]{3}{*}{0.605} \\
\hline Employee & 137 & 54 & 78 & 5 & \\
\hline House wife & 103 & 36 & 61 & 6 & \\
\hline \multicolumn{5}{|l|}{ Income } & \multirow[t]{4}{*}{0.139} \\
\hline more than $1000-2000 \mathrm{LE}$ & 141 & 46 & 88 & 7 & \\
\hline More than $2000-3000 \mathrm{LE}$ & 86 & 36 & 46 & 4 & \\
\hline More than $3000 \mathrm{LE}$ & 13 & 8 & 5 & 0 & \\
\hline \multicolumn{5}{|l|}{ Number of family members } & \multirow[t]{5}{*}{0.143} \\
\hline 2 & 33 & 9 & 19 & 5 & \\
\hline $3-4$ & 107 & 42 & 61 & 4 & \\
\hline $5-6$ & 88 & 36 & 50 & 2 & \\
\hline more than 6 & 12 & 3 & 9 & 0 & \\
\hline Enrolled in lectures & 66 & 32 & 32 & 2 & 0.100 \\
\hline Any source of information & 25 & 6 & 15 & 4 & $0.019 *$ \\
\hline Audiovisual & 39 & 14 & 25 & 0 & 0.347 \\
\hline Physician & 45 & 16 & 28 & 1 & 0.776 \\
\hline Media & 140 & 65 & 69 & 6 & $0.003 *$ \\
\hline Others & 28 & 10 & 18 & 0 & 0.614 \\
\hline Food poisoning case & 64 & 20 & 42 & 2 & 0.380 \\
\hline
\end{tabular}

* $P$ - value is significant

$\chi^{2}$ Chi-square test

* Statistical significant difference $(\mathrm{P}<0.05)$

${ }^{a} P$-value for either Chi-square (Number of cases $>5$ ) or Fisher exact test (for otherwise).

Table (6): This table showed that there was a statistical significant relation between total level of knowledge and marital status with $(p$-value $=0.013)$, educational level with $(p$-value $=0.012)$, and any source of information with $(p$-value $=0.019)$, and source of information from media with (p-value 0.003 ). And there is no statistical relation between level of knowledge and other socio demographic characteristics. 
Table (7): Relationship between some socio demographic characteristics of the studied mothers and their total level of behavior regarding food safety $(\mathrm{N}=\mathbf{2 4 0})$

\begin{tabular}{|c|c|c|c|c|}
\hline \multirow[t]{2}{*}{ Socio-demographic data } & \multirow[t]{2}{*}{$\mathbf{N}$} & \multicolumn{2}{|c|}{ Total level of behavior } & \multirow[t]{2}{*}{$P$-value } \\
\hline & & Satisfactory $(n=107)$ & Good $(n=133)$ & \\
\hline Mother age / years & & & & 0.053 \\
\hline $18-29$ & 87 & 39 & 48 & \\
\hline $30-39$ & 88 & 41 & 47 & \\
\hline $40-49$ & 40 & 12 & 28 & \\
\hline $50-59$ & 23 & 15 & 8 & \\
\hline 60 and more & 2 & 0 & 2 & \\
\hline \multicolumn{4}{|l|}{ Marital status } & \multirow[t]{4}{*}{0.103} \\
\hline Married & 217 & 99 & 118 & \\
\hline Widow & 9 & 1 & 8 & \\
\hline divorced & 14 & 7 & 7 & \\
\hline \multicolumn{4}{|l|}{ Education Level } & \multirow[t]{5}{*}{0.237} \\
\hline Illiterate & 16 & 7 & 9 & \\
\hline Read and write & 23 & 12 & 11 & \\
\hline secondary education & 115 & 58 & 57 & \\
\hline University education & 86 & 55 & 31 & \\
\hline \multicolumn{4}{|l|}{ Working state } & \multirow[t]{3}{*}{0.120} \\
\hline Employee & 137 & 67 & 70 & \\
\hline House wife & 103 & 40 & 63 & \\
\hline \multicolumn{4}{|l|}{ Income } & \multirow[t]{4}{*}{0.483} \\
\hline $1000-2000 \mathrm{LE}$ & 89 & 36 & 53 & \\
\hline More than $2000-3000 \mathrm{LE}$ & 86 & 43 & 43 & \\
\hline More than $3000 \mathrm{LE}$ & 13 & 7 & 6 & \\
\hline \multicolumn{4}{|l|}{ Number of family members } & \multirow[t]{5}{*}{$0.021 *$} \\
\hline 2 & 33 & 11 & 22 & \\
\hline $3-4$ & 107 & 54 & 53 & \\
\hline $5-6$ & 88 & 41 & 47 & \\
\hline more than 6 & 12 & 1 & 11 & \\
\hline Enrolled in lectures & 66 & 23 & 43 & 0.062 \\
\hline Any source of information & 25 & 8 & 17 & 0.181 \\
\hline Audiovisual & 39 & 16 & 23 & 0.625 \\
\hline Physician & 45 & 25 & 20 & 0.100 \\
\hline Media & 140 & 66 & 74 & 0.345 \\
\hline Others & 28 & 11 & 17 & 0.548 \\
\hline Food poisoning case & 64 & 19 & 45 & $0.005 *$ \\
\hline
\end{tabular}

* $P$ - value is significant

$\chi^{2}$ Chi-square test $\quad *$ Statistical significant difference $(\mathrm{P}<0.05)$

${ }^{a} P$-value for either Chi-square (Number of cases $>5$ ) or Fisher exact test (for otherwise).

Table (7): This table showed that there was a statistical significant relation between total level of behavior and number of family members $(\mathrm{p}$-value $=0.021)$ and food poisoning case $=(0.005)$ and there is no statistical significant relation between total level of behavior and other socio-demographic characteristics.

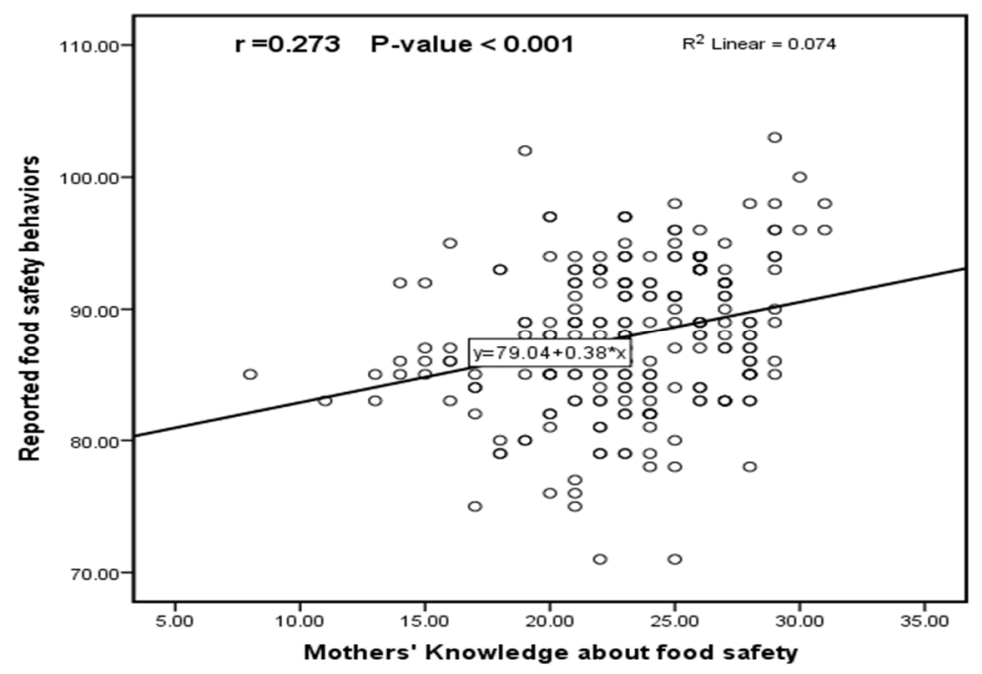

Figure (1): Correlation between scores of knowledge and the reported behavior of the studied mothers in food safety.

Fig (3): It was found that there was positive low correlation $(0.38)$ between knowledge score and reported behavior score of the studied mothers in food safety. 


\section{Discussion:}

Based on the result of the present study, it has been noticed that out of 240 of total participants mothers whose age ranged from eighteen to thirty yrs. with mean age (Mean \pm SD $35.05 \pm 9.90)$, this may be due to that mothers at this age are more responsible for food preparation in early adult hood, and this confirmed by Hassan, et al., (2014) in lebnan which reported that mothers are more responsible for food preparation in early adult hood.

These findings were compatible with Zyoud, et al., (2019) in Plastiene who cited in their study about knowledge, attitude and practices among parents regarding food poisoning that the mean age of respondents was 29.62 years $(S D \pm 6.380)$ and the median was 29.0 years with an interquartile range of 25.0-34.0, also current findings agree with (Seksaria, S \& Sheth, M. K. (2014) in INDIA, who said that the average age of the mothers was 25 yrs.

This finding in line with (Meysenburg et al., 2014) in Midwestern states "USA" who found that less than one third of the primary food preparers their age was more than 35 years old, Also this result was inconsistent with (Alqurashi et al., 2019) in Saudi Arabia who found that more than half of the studied sample aged 20-30 years old

The present study illustrated that most of the participant were married $(90.4 \%)$ and less than quarter $(7.5 \%)$ were with secondary education and also about $(7 \%)$ were with university education, and half of them $(50 \%)$ were illiterate, this related to that our participant were collected from villages and the Egyptian rural culture not allow for the women to attend or complete their education level which was confirmed by (Ali and Gurmu,2018) who said that Upper and Lower Egyptian rural culture not allow for women to go to school or complete their education level, this result is in the same line with (Alqurashi et al., 2019) in Saudi Arabia who found that less than one third of the studied sample have high school education. In contrast, FAO, (2017), reported in their survey that, the majority $(55.5 \%)$ of the sampled household held less than secondary education among them (28.2\%) have completed only elementary education or less, while $(9.1 \%)$ are illiterate.

According to occupation the present study found that more than two third of the studied women(83\%) were housewives, this finding incompatible with (Stenger et al., 2014) in Hispanic families who found that less than half of the studied mothers were unemployed.

In relation to previous training the current study found that the majority of sample of the studied mothers $(90 \%)$ are not enrolled in any training, lectures or seminars about food safety, and (90\%) of them have not any formal information resources as for food safety which was confirmed by (Tariku, et al., 2018) in northeast Ethiopia who reported in their study that $(90 \%)$ of the respondents did not take formal training on food handling.

Regarding to Mean score of knowledge for studied mothers regarding food safety, the current study mentioned that knowledge about hygiene during food preparation was represent the highest knowledge for studied mothers and knowledge about cooking food represent the lowest knowledge, this justification was confirmed by (Langiano, et al., 2012) in Cassino, Italy whose study highlight that while mothers in Saudi Arabia have generalized knowledge about food storage they lack a detailed understanding which impacts their practices
As regard to the total level of knowledge and behavior of the studied mothers regarding to food safety, the current study founded that more than half of the studied mothers have poor knowledge level (57.9\%) and less than half of the studied mothers have satisfactory behavioral level, $(42.9 \%)$ and less than two third $(55.4 \%)$ reported poor behavioral level. In the same line Mohammed, A. E., et al., (2019) in Assiut reported in their study that one thirds of the studied mothers have poor level of reported practices.

And this finding was not similar to (Mendagudali, et. al., 2016) in Kalaburagi, Karnataka who found that more than three quarters of the studied women have good level of reported practices. Also Fawzi, M., and Shama. (2019) in Egypt reported that women working in Alexandria University, Egypt were very knowledgeable with regard to personal hygiene. Moreover in others studies have also suggested that food handlers have a significantly good knowledge of personal hygiene. Lum, et. al., (2013) also report that food handlers are knowledgeable with regard to food poisoning; and Ahmed (2015) in Yemen, however, reported that in Yemen mothers' knowledge about food poisoning was not satisfactory.

As regard to relationship between some socio demographic characteristics of the studied mothers and their total level of behavior regarding food safety the current study found that there was a statistical significant relation between total level of behavior and number of family members.

In the present study, it has been noticed a good positive correlation between knowledge score and reported behavior score of the studied mothers in food safety. These reflect a high importance of studied mothers' knowledge about food safety food poisoning prevention. This is consistent with (Zyoud, et al., (2019) who stated that a significant modest positive correlation was shown between respondents' knowledge and attitude scores regarding food poisoning $(r=0.240, p<0.001)$. The results mean that respondents who had good knowledge were more likely to have a good attitude towards food poisoning.

Also was similar to (Alqurashi et al., 2019) who found that there was a significant positive correlation $(\mathrm{p} \leq$ 0.01 ) between food safety knowledge and food safety practices. the present study indicated that food safety knowledge could statistically predict food safety practices that's because the food handling knowledgeable mother can easily do good practice during food handling better than others mothers who don't have knowledge about food handling.

Moreover in the same line with Elinda, et al., (2020) in Indonesia who found in their study that Food safety knowledge affects food safety attitude and behavior significantly, therefore, there is a need to improve food safety knowledge in order to improve food safety attitude and behavior of the communities.

Respondents with a high level of education reported higher knowledge scores than those with a lower level. In addition, respondents who live in a city or village reported higher scores than those living in camps. Another important finding was that age affects knowledge score, but the association was not significant. Surprisingly, gender affected neither knowledge nor attitude but significantly affected practice. This finding further supports the idea that females are more informed about appropriate food handling behaviors. 


\section{Conclusion:}

Based on the results of the present study we can be concluded that:

There about less than third of the studied mothers having knowledge about the correct strategies that guarantee food safety, although the majority having knowledge about wash vegetables under running water well, washing hands with soap and water before preparing food, and three third of them having knowledge about the best way to know that chicken has been cooked long enough. Knowledge about hygiene during food preparation was represent the highest knowledge for studied mothers and knowledge about cooking food represented the lowest knowledge. Most of participants were wash their hands with running water and soap before preparing food, and also wash their hands immediately after handling raw meat.

The current study founded that there was a statistical significant relation between total level of behavior and number of family members, and more than half of the studied mothers have poor knowledge level and less than half of the studied mothers have satisfactory behavioral level and more than one third reported poor behavior and there was a good positive correlation between knowledge score and reported behavior score of the studied mothers in food safety, these reflect a high importance of studied mothers' knowledge about food safety food poisoning prevention.

\section{Recommendations}

Based on the findings of the present study, the researcher come up with the following recommendations:

\section{Recommendations for Mothers:}

- Increase Mothers awareness about the prevention of food borne disease and how to provide a safer food for family members that affects their health and their quality of life.

\section{Recommendations for community nurse:}

- Nurses should emphasize to provide an educational program tailored to each mother in the community about food safety.

\section{Recommendations for the community:}

- Use public awareness campaigns to positively influence consumers' attitudes and practices, encouraging them to exercise caution when buying, storing, handling and preparing food.

- Develop public health enforcement authorities to monitor the adherence of food stores to the required safety standards.

- Develop and equip more community health centers with audio tapes, video tapes, pamphlets, leaflets, magazines, and books.

- It is recommended that female illiteracy problem must be eradicated because it is associated to every family member's health. In addition, increase the community awareness about food borne disease prevention and how to provide a safer food for family members through mass media especially television, or the internet.

- Establishment of hot line (phone and net) contact for urgent consultations.

- Strengthening of rural health centers association.
- Healthcare organizations must develop a dedicated funding plan that supports health education about healthy food and food borne illness.

\section{Recommendations for further research:}

- Re-apply of the current study on a larger sample size to achieve generalizable results.

- More research on evaluation of the impact of try to find a solution on how to educate the people especially the food handlers to practice correct hygiene measures.

- Another research can also be done to determine the most effective ways to reduce contamination from the farm in the first place.

\section{References:-}

(1) Alqurashi, N., Priyadarshini, A., \& Jaiswal, A., (2019): Evaluating Food Safety Knowledge and Practices among Foodservice Staff in Al Madinah Hospitals, Saudi Arabia, Safety VOL. 5, 9PP.1- 19

(2) Basavanthappa B.T., (2016): Infectious Disease, text book of Community Health Nursing, voll third edition, chapter 21, pp. 245:246.

(3) Elinda-Patra, M. W., Dewanti-Hariyadi, R., \& Nurtama, B. (2020). Modeling of food safety knowledge, attitude, and behavior characteristics. Food Research, 4(4), 1045-1052.

(4) Fawzi, M., \& Shama, M. E. (2019). Food safety knowledge and practices among women working in Alexandria University, Egypt. Egypt Public Health Assoc, 84(1), 9517.

(5) Gemeda, T. E., Asayehu, T. T., Abdisa, M., and Fekadu, H. (2018). Assessment of knowledge, attitude and practices of food handlers in nekemtereferral hospital, Wollega, Ethiopia. J Nutr Health Food Eng, 8(1), 00262.

(6) Hassan, H. F., \& Dimassi, H. (2014). Food safety and handling knowledge and practices of Lebanese university students. Food control, 40, 127-133.

(7) Langiano, E.; Ferrara, M.; Lanni, L.; Viscardi, V.; Abbatecola, A.M.; De Vito, E. Food safety at home:Knowledge and practices of consumers. J. Public Health 2012, 20, 47-57. [CrossRef] [PubMed]

(8) Lum A., Albrect J., Yaseen M., Litchfield R., \& Rittergooder P., (2013): Food-handling practices and knowledge among families with young children. Food protection trends Vol.1pp 358-375.

(9) Meysenburg, R., Albrecht, J. A., Litchfield, R., \& RitterGooder, P. K. (2014). Food safety knowledge, practices and beliefs of primary food preparers in families with young children. A mixed methods study. Appetite, 73, 121131.

(10) Mendagudali, R. R., Akka, K. D., Swati, I. A., Shedole, D. T., \& Bendigeri, N. (2016). Knowledge, attitude, and practices of food safety among women of Khaza bazar, the urban field practice area of KBN Institute of Medical Sciences, Kalaburagi, Karnataka. International Journal of Medical Science and Public Health, 5(3), 516-520.

(11) Mohammed, A. E., Mohammed, S. A., \& Abd Elaty, N. S. (2019). Assessment of Knowledge and Reported Practices of Mothers Regarding Food Handling Among Their Preschool Children in AbuTig District. Assiut Scientific Nursing Journal, 7(19), 175-185.

(12) Mutisya M, Ngware MW, Kabiru CW, Kandala N-b. 2016. The effect of education on household food security in two informal urban settlements in Kenya: a longitudinal analysis. Food Security ; 8(4):743-56.

(13) Seksaria, S. A., \& Sheth, M. K. (2014). Maternal knowledge and practices towards sanitation and their relationships with occurrence of diarrhoea in 
children. International Journal of Public Health Science, 3(3), 206-212.

(14) Sines, D., Aldridge-Bent, S., Fanning, A., Farrelly, P., Potter, K., \& Wright, J. (Eds.). (2013). Community and public health nursing. John Wiley \& Sons.

(15) Stenger K., Ritter-Gooder P., Perry C., \& Albrect J., (2014): Amixed methods study of food safety knowledge, practices and beliefs in Hispanic families with young children.Appetite.Vol.83 pp.194-201.

(16) Tariku, A., Seid, E., Derseh, L., Derso, T., Assefa, M., Gonete, K. A., \& (2018). Nutrient consumption and associated factors among school age children in Dewa
Chefe District, northeast Ethiopia: a cross-sectional study. BMC research notes, 11(1), 1-8.

(17) Zeeshan M, Shah H, Durrani Y, et al. A QuestionnaireBased Survey on food safety knowledge during FoodHandling and food preparation. Practicies among University Students. Clin Nutr Diet. 2017 , 3:2. doi:10.4172/2472-1921.100052.

(18) Zyoud, S. E., Shalabi, J., Imran, K., Ayaseh, L., Radwany, N., Salameh, R., ... \& Al-Jabi, S. (2019). Knowledge, attitude and practices among parents regarding food poisoning: a cross-sectional study from Palestine. BMC public health, 19(1), 1-10. 